\title{
Speed Sensorless Variable Structure Torque Control of Induction Motor
}

UDK 621.313.333.072.1

IFAC $5.5 .4 ; 4.0 .1$

Original scientific paper

\begin{abstract}
Induction motor speed sensorless torque control, which allows operation at low and zero speed, optimizing both torque response and efficiency, is proposed. The control is quite different than the conventional field-oriented or direct torque controls. A new discontinuous stator current FPGA based controller and rotor flux observer based on sliding mode and Lyapunov theory are developed, analyzed and experimentally verified. A smooth transition into the field weakening region and the full utilization of the inverter current and voltage capability are possible. The reference tracking performance of speed and rotor flux is demonstrated in terms of transient characteristics by experimental results.
\end{abstract}

Key words: Discrete-event driven system, FPGA, Induction motors, Sliding mode control, Torque control

Strukturno promjenjivo upravljanje momentom asinkronog motora bez mjernog člana brzine vrtnje. Predloženo je upravljanje momentom asinkronog motora bez mjernog člana brzine vrtnje, koje omogućuje rad na malim brzinama i u stajanju te pritom optimira i odziv momenta i učinkovitost. Predloženo je upravljanje prilično drugačije od konvencionalnog upravljanja poljem i neposrednog upravljanja momentom. Razvijeni su, analizirani i eksperimentalno potvrđeni novi diskontinuirani regulator struje statora implementiran u FPGA i estimator rotorskog magnetskog toka zasnovan na kliznim režimima i Ljapunovljevoj teoriji. Omogućeni su glatki prijelaz u područje slabljenja polja i puna iskoristivost strujno-naponskih mogućnosti napojnog pretvarača. Performanse slijeđenja referentne veličine brzine vrtnje i rotorskog magnetskog toka pokazane su eksperimentalno dobivenim prijelaznim pojavama.

Ključne riječi: sustav vođen diskretnim događajima, FPGA, asinkroni motori, upravljanje zasnovano na kliznom režimu, upravljanje momentom

\section{INTRODUCTION}

Recent theoretical advances in the field of hybrid and discrete event-systems, and significant increase of the computational power available for the control of the power electronic systems, invite both control and power electronics communities to adapt traditional control schemes associated with power electronics applications. In order to raise the performance and efficiency of the drive applications, faster and more sophisticated current control schemes are required. The conventional current control scheme consists of discrete-time PI current controller and pulse-width modulator. It is replaced with the new sequential switching current control strategy [1]. Hysteresis controllers can be a good alternative for such applications. They are robust to system parameter variations, exhibit very good dynamics, require simple implementation and enable direct control of the bridge transistors without special modulators. Their main drawback is a limited control of transistor switching frequency $[2,3]$.
In this paper, a novel switching sliding mode controller for a voltage-source inverter is presented, which is suitable for very simple and inexpensive FPGA (FieldProgrammable Gate Array) hardware implementation. Its main properties are robustness and fast dynamic response. When joined they reduce inverter switching frequency required to keep the current error within a tolerance region of given length. Moreover, a very simple and low cost implementation is possible owing to the use of FPGA finite state automation implementation.

In this paper, by combining the variable structure system and Lyapunov design [4], a novel sliding mode algorithm of controller/observer for induction motor is developed. This control method is based on estimation of the rotor flux and speed of induction motor (IM). Due to use of sliding mode principle it is robust against variation of load torque, machine parameters and external disturbances. The sliding mode principles, based on state variable errors, are used as feedback control to guarantee stability of control 
system. The proposed method is investigated and verified experimentally using hardware in the loop simulation.

The paper is organized as follows. In Sect. 2 dynamic model of IM, together with control system design is presented. Sect. 3 presents proposed variable structure control (VSC) current and flux control schemes with developed new decision logic-based event-driven controller. Sect. 4 describes the new rotor flux observer based on continuous sliding mode control. Acquired models are experimentally confirmed using in house developed DSP/FPGA board [5]. Mapping of the obtained models into FPGA executable code is presented in Sect. 5. Experimental results are presented in Section 6. The findings and the comments of presented approach are discussed in the conclusion.

\section{CONTROL SYSTEM DESIGN}

\subsection{Machine Dynamics}

The dynamics of IM consist of mechanical motion, dynamics of stator electromagnetic system and the dynamics of the rotor electromagnetic system with electromagnetic torque developed by machine:

$$
\begin{gathered}
\frac{d \omega_{r}}{d t}=\frac{1}{J}\left(T_{e}-T_{L}\right) \\
\frac{d i_{s}^{s}}{d t}=\frac{1}{L_{s}-L_{m}^{2} / L_{r}}\left(u_{s}^{s}-R_{s} i_{s}^{s}-\frac{L_{m}}{L_{r}} \frac{d \Psi_{r}^{s}}{d t}\right) \\
\frac{d \Psi_{r}^{s}}{d t}=\frac{R_{r}}{L_{r}} L_{m} i_{s}^{s}-\left(\frac{R_{r}}{L_{r}}-j p \omega_{r}\right) \Psi_{r}^{s} \\
i_{s}^{s}=\frac{1}{L_{s}-L_{m}^{2} / L_{r}}\left(\Psi_{s}^{s}-\frac{L_{m}}{L_{r}} \Psi_{r}^{s}\right) \\
T_{e}=\frac{3}{2} p \frac{L_{m}}{L_{r}}\left(\Psi_{r}^{s} \times i_{s}^{s}\right)
\end{gathered}
$$

where $\omega_{r}$ is mechanical rotor angular speed, the two dimensional complex space vectors $\Psi_{s}^{s}=\left[\Psi_{s a}^{s} \Psi_{s b}^{s}\right]^{\top}$, $\Psi_{r}^{s}=\left[\Psi_{r a}^{s} \Psi_{r b}^{s}\right]^{\top}, u_{s}^{s}=\left[u_{s a}^{s} u_{s b}^{s}\right]^{\top}, i_{s}^{s}=\left[i_{s a}^{s} i_{s b}^{s}\right]^{\top}$ are stator and rotor flux, stator voltage and current, respectively, $T_{e}$ is electromagnetic motor torque, $T_{L}$ is load torque, $J$ is inertia of the rotor and $p$ is the number of pole pairs of the machine. $R$ stands for resistance and $L$ for inductance. The meaning of the subscript and superscript are as follows: $s$ is stator, $r$ is rotor, and $m$ is mutual $\left(L_{m}\right.$ is mutual inductance). The subscript denotes the location of variable and superscript denotes the frame of references.

One of the most important issue in implementing control of induction machine, either direct torque control (DTC) or field oriented control (FOC) strategies is to obtain real-time instantaneous flux magnitude and its position with sufficient accuracy for the entire speed range $[2,6,7]$. The difficulty of flux estimation lies in the nonlinear induction machine dynamics, which is characterized by speed dependent and time varying parameters [8].

\subsection{Sliding Mode Control System Design}

The design of sliding mode system can generally be presented as two-step procedure: design of the switching manifold and design of the control that enforces sliding mode. The switching manifold must be selected in such a manner to guaranty desired system. The procedure may be presented as follows [9]:

1. From the system specification select the vector function $\sigma=\sigma\left(x^{d}, x\right)$ where $x^{d}$ represents desired values of the controlled vector variable $x$, so that design specifications are met if the sliding mode is enforced in manifold:

$$
S=\left\{x: \sigma=\sigma\left(x^{d}, x\right)=0\right\} .
$$

2. Select the control input so that the attractiveness and the stability of the solution $\sigma=\sigma\left(x^{d}, x\right)=0$ is guaranteed.

Since fulfillment of the design requirements is reduced to the stability of (6) natural selection of the Lyapunov function candidate is presented in the following form:

$$
V=-\sigma^{T} \sigma / 2 \quad \text { and } \quad \dot{V}=\sigma^{T} \dot{\sigma} .
$$

This selection guaranties that $\left.V\right|_{\forall \sigma \neq 0}>0$ and $\left.V\right|_{\sigma=0}=0$. The Lyapunov stability requirement is fulfilled, if such a control can be selected that $\left.\dot{V}\right|_{\forall \sigma \neq 0}<0$ and $\left.\dot{V}\right|_{\sigma=0}=0$. This objective can be achieved, if the following is satisfied:

a) The derivative $\dot{V}$ of the Lyapunov function is function of control (derivative of function $\sigma=\sigma\left(x^{d}, x\right)=0$ must be function of control);

b) There is such a function $\Phi(\sigma)$ so that $\left.\sigma^{T} \Phi(\sigma)\right|_{\forall \sigma \neq 0}<0$; and

c) There is a unique solution for control for the following equality:

$$
\dot{V}=\sigma^{T} \dot{\sigma}(u)=\sigma^{T} \Phi(\sigma)<0 .
$$

There are many different ways for selecting $\Phi(\sigma)$. For the application in electrical drive control, two particular forms as given in (8) may be of interest:

$$
\dot{V}=\sigma^{T} \Phi(\sigma)<0 \Rightarrow\left\{\begin{array}{l}
\Phi(\sigma)=-\Gamma \operatorname{sign}(\sigma), \\
\Phi(\sigma)=-D \sigma, D \succ 0,
\end{array}\right.
$$

where $\Gamma$ is positive definite diagonal or matrix with predominant diagonal, $\operatorname{sign}(\sigma)=$ 


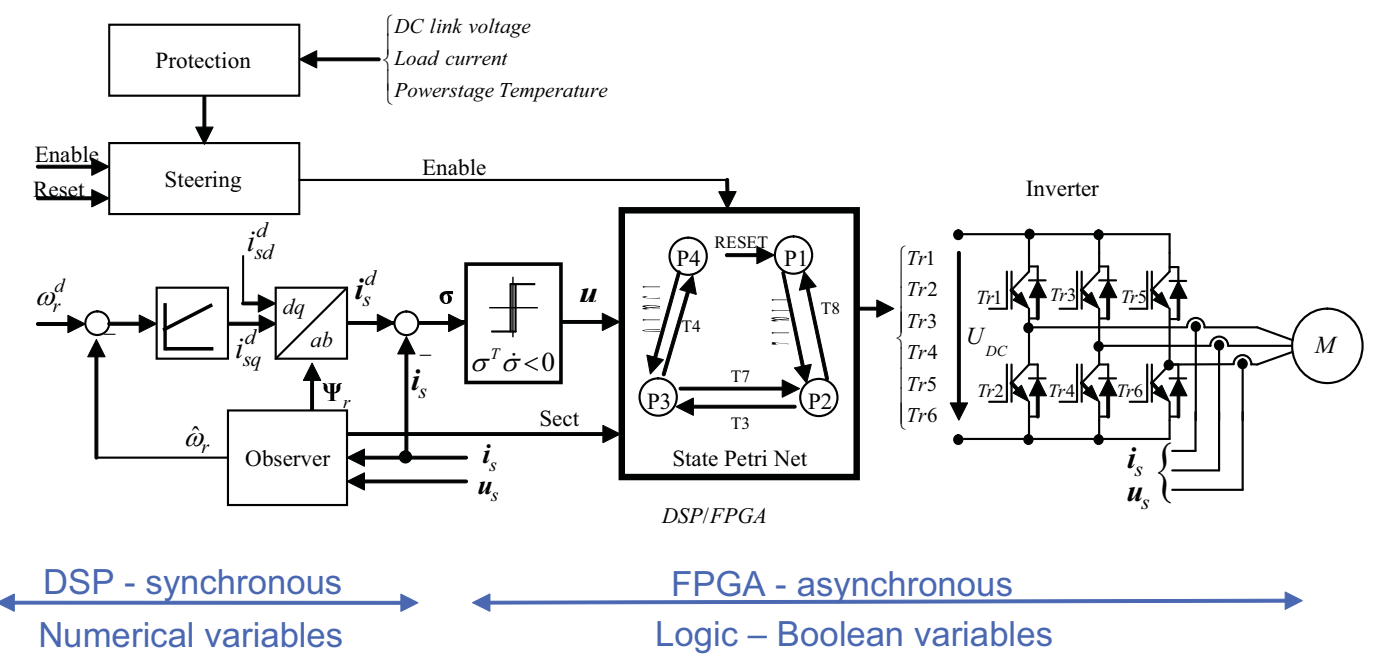

Fig. 1. Block diagram of event-driven sliding mode control of IM

$\left[\operatorname{sign}\left(\sigma_{1}\right), \ldots, \operatorname{sign}\left(\sigma_{m}\right)\right]^{\top}$ and $D$ is positive definite matrix. It should be stated here that the second choice in (9) actually guaranties asymptotical stability and thus does guarantee sliding mode motion. However for time $t>t_{0}$ the motion stays in the $\epsilon$ vicinity of the sliding mode manifold.

For vector function $\Phi(\sigma)=-\Gamma \operatorname{sign}(\sigma)$ resulting control is discontinuous and manifold (6) is reached in finite time.

Many systems, for example estimators and observers, do not support switching operation well. For this application the choice for $\Phi(\sigma)$ is selected as $\Phi(\sigma)=$ $-D \sigma, D \succ 0$ which results in the continuous control with asymptotic stability of the solution $\sigma=\sigma\left(x^{d}, x\right)=0$. The continuous control function is then:

$$
u(t)=u_{e q u}+(G B)^{-1} \sigma
$$

where $u_{e q u}$ is so-called equivalent control and is continuous function [9]. Since the control presented in this paper is switching by its nature, $\Phi(\sigma)=-\Gamma \operatorname{sign}(\sigma)$ was used.

\section{PROPOSED VSC CURRENT AND FLUX CON- TROL SCHEME}

The aim of this paper is to present an application of switching control in switching power converters, which use the finite state machine principle embedded in FPGA environment. With the use of logic event driven approach we intend to present the operation of switching converters, which are represented as the set of energy storage elements with their interconnections dynamically changed by the operation of the switching matrix [10]. The switching matrix explains the role of switching elements that determine the power exchange between energy storage elements. By the introduction of switching into the structure of the system the design in the framework of switching control is made a natural choice.

Considering the operation of an IM together with the inverter, a discrete event-driven approach can be introduced [3,10] (Fig. 1). The inverter is connected to the DC-link voltage and its operation is based on the transistor switching pattern. Instantaneous dynamics of the control are determined. Different transistor switch pattern results in different plant dynamics. Applying proper switching among these plant dynamics, the system can track the desired reference trajectory. Switching pattern of each transistor is considered as a discrete state of the system and the changing of the transistor switching pattern is considered as a transition of the system among discrete states. The transition of the discrete system between discrete states can be considered as occurrence of an event. To control transitions of the system among the discrete states, some additional conditions are introduced.

Considering the vector current errors as conditions for the transitions, a discontinuous current control $\Phi(\sigma)=$ $-\Gamma \operatorname{sign}(\sigma)(9)$ is achieved, which is fast, robust and simple for implementation.

To achieve safe and manageable drive operation, monitoring and protection functions should be included. They are event-driven inherently, as they react on the change of logic conditions. If they are combined with the proposed discontinuous current control and rotor flux observer, over- 
all functionality of the drive can be systematically described by Fig. 1 .

To control the stator current, the sector of momentary inverter voltage $u_{s}$ is recognized first. The new output voltage vector (the transistor switching pattern) for the stator current control is selected respecting the current control error and Lyapunov stability condition. Considering space vector representation of the inverter stator voltage $u_{s}$, it is represented as vector rotating around the origin (Fig. 2). Six active switching vectors of the three phase transistor bridge result in six output voltage vectors denoted as $V_{1}, \ldots, V_{6}$. According to the signs of the IM terminal phase voltages $u_{s 1}, u_{s 2}$ and $u_{s 3}$, the phase plane is divided into six sectors denoted with Su1,..,Su6.

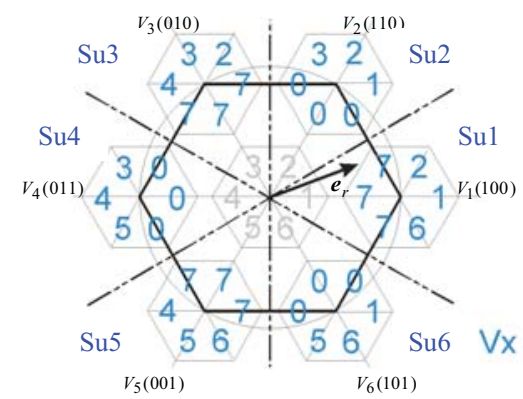

Fig. 2. Stator voltage $u_{s}$ sector allocation spaces

The situation presented in Fig. 2, where the stator voltage space vector $u_{s}$ is in sector 1 , is the following. In this sector voltage vectors $V_{0}, V_{7}, V_{1}, V_{2}$ and $V_{6}$ are selected for the IM current control. $V_{0}, V_{7}$ are two zero vectors, while $V_{1}, V_{2}, V_{6}$ are nearest adjacent live output voltage vectors to this sector. With the use of the discrete event system theory, five output voltage vectors $V_{0}, V_{7}, V_{1}, V_{2}$ and $V_{6}$ are recognized as possible discrete states of the system. The resulting events represent allowed transitions among the discrete states i.e. allowed switching patterns. The structure of the proposed strategy is represented by Petri Net graph (Fig. 3) [11].

Switching among the available output voltage vectors in each sector is determined by conditions that originate from the derivative of the Lyapunov function. For the Lyapunov function candidate

$$
V=\frac{1}{2} \sigma^{T} \sigma=\frac{1}{2}\left(i_{s}^{d}-i_{s}\right)^{T}\left(i_{s}^{d}-i_{s}\right)
$$

the stability requirement is fulfilled if such a control can be selected, that the derivative of the Lyapunov function candidate is negative $\dot{V}=\sigma^{T} \dot{\sigma} \leq 0 \times$ Derivatives of current control error may be expressed with the voltage equation:

$$
\frac{d}{d t}\left(i_{s}^{d}-i_{s}\right)=\frac{d}{d t} i_{s}^{d}-\frac{1}{L_{s}-L_{m}^{2} / L_{r}}\left(u_{s}-R_{s} i_{s}-e_{r}\right),
$$

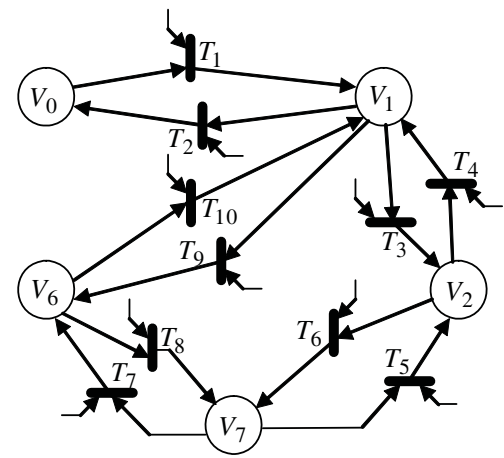

Fig. 3. PN-graph of the switching sequence in Sector 1

where $i_{s}^{d}, i_{s}$ are desired and actual stator current of motor, $u_{s}$ is voltage control input, $R_{s} i_{s}$ is resistive voltage drop and $e_{r}$ is electromotive force (EMF) of the motor.

The conditions for the sequential switching of the power inverter are selected as:

$$
\begin{aligned}
& S_{R}=\frac{1}{2}(1-\operatorname{sign}(A)), \\
& S_{S}=\frac{1}{2}(1-\operatorname{sign}(B)), \\
& S_{T}=\frac{1}{2}(1-\operatorname{sign}(C)),
\end{aligned}
$$

where

$$
\begin{aligned}
& A=\left(i_{s a}^{d}-i_{s a}\right) \\
& B=-\left(i_{s a}^{d}-i_{s a}\right) / 2-\sqrt{3}\left(i_{s b}^{d}-i_{s b}\right) / 2 \\
& C=-\left(i_{s a}^{d}-i_{s a}\right) / 2+\sqrt{3}\left(i_{s b}^{d}-i_{s b}\right) / 2
\end{aligned}
$$

which is evolved from the Lyapunov function derivative. When $U_{D C}$ has enough magnitude that $\dot{V} \leq 0$, than $V \rightarrow$ 0 and $i_{s} \rightarrow i_{s}^{d}$. Notice that if $S_{R}, S_{S}, S_{T}$ equal to zero simultaneously, no current is delivered to the motor.

The main disadvantage of the sliding mode control is in the significant transistors switching frequency variations due to the changing operating point or load variations, as well as in the difficulties to fold back or even limit the short circuit output current with sliding mode output voltage control [3].

The proposed logic event-driven stator current control is similar to DTC and can be realized in the form described in Table 1, where states of stator current control error are presented by $\operatorname{sign}\left(D_{i}\right)\left(D_{i}=S_{R}, S_{S}, S_{T}\right)$ and currently active voltage sector is presented by $\operatorname{sign} U$ $\left(U=u_{S 1}, u_{S 2}, u_{S 3}\right)$. Formulas for $S_{R}, S_{S}$ and $S_{T}$ are presented in (13), whereas allocation of voltage sector is presented in Fig. 2. To further improve the presentation, active voltage vectors are marked in Table 1 by gray background. Because the transition between inverter switch states is performed by switching only one inverter leg simultaneously, the chattering in stator current caused by inverter switching (and consequently torque chattering) is reduced. 
Table 1. Look-up Table

\begin{tabular}{|c|c|c|c|c|c|c|c|}
\hline \multicolumn{2}{|c|}{$\operatorname{sign} U$} & Su1 & Su2 & Su3 & Su4 & Su5 & Su6 \\
\cline { 3 - 8 } $\operatorname{sign} D_{i}$ & & 100 & 110 & 010 & 011 & 001 & 101 \\
\hline Sdi0 & 000 & V7 & V0 & V7 & V0 & V7 & V0 \\
\hline Sdi1 & 100 & V1 & V1 & V7 & V0 & V7 & V1 \\
\hline Sdi2 & 110 & V2 & V2 & V2 & V0 & V7 & V0 \\
\hline Sdi3 & 010 & V7 & V3 & V3 & V3 & V7 & V0 \\
\hline Sdi4 & 011 & V7 & V0 & V4 & V4 & V4 & V0 \\
\hline Sdi5 & 001 & V7 & V0 & V7 & V5 & V5 & V5 \\
\hline Sdi6 & 101 & V6 & V0 & V7 & V0 & V6 & V6 \\
\hline Sdi7 & 111 & V7 & V0 & V7 & V0 & V7 & V0 \\
\hline
\end{tabular}

The reference current can now be calculated simply as:

$$
i_{s}^{d}=\frac{\left|\hat{\Psi}_{r}\right|}{L_{m}}+j \frac{2}{3 p} \frac{L_{r}}{L_{m}} \frac{T_{e}^{d}}{\left|\hat{\Psi}_{r}\right|} .
$$

The orientation value required for the dq-ab transformation used in conventional current control is performed applying the components of the rotor flux, which are directly employed:

$$
e^{j \Theta}=\cos \Theta+j \sin \Theta=\frac{\hat{\Psi}_{r a}}{\left|\hat{\Psi}_{r}\right|}+j \frac{\hat{\Psi}_{r b}}{\left|\hat{\Psi}_{r}\right|}=\frac{1}{\left|\hat{\Psi}_{r}\right|} \hat{\Psi}_{r} .
$$

The advantage of proposed transformation is that the sin and cos function are replaced with multiplication in the applied FPGA algorithm.

\section{ROTOR FLUX OBSERVER}

The rotor flux observer, presented in this work, is based on the stator equation, where the derivative of the estimated stator flux is calculated from measured stator voltage and current $[7,12]$. The observer equation (17) represents the first order vectorial differential equation. The stator voltage $u_{s}$ and current $i_{s}$ serve as control input to the estimated stator flux $\hat{\Psi}_{s}$. In order to avoid voltage error influence due to inverter non-linear behavior, the measured value of the stator voltage is used instead of the commonly used reference voltage:

$$
\frac{d}{d t} \hat{\Psi}_{s}=\hat{u}_{s}-\hat{R}_{s} i_{s}+\hat{u}_{k}
$$

Non-modeled dynamic is set as a remaining signal $\hat{u}_{k}$, calculated from the magnitude error of the rotor flux $\left|\Delta \Psi_{r}\right|$.

The stator parameters of the IM appear in the rotor flux observer; i.e. stator resistance $\hat{R}_{s}$ and stator inductance $\sigma \hat{L}_{s}$. The influence of the stator inductance variation is small, but stator resistance changes significantly during the operation.

The stator resistance parameter mismatch influences both, the amplitude and the orientation error of the estimated rotor flux. It has the highest influence in the lowspeed region, combined with the applied load torque. This effect is used to obtain stator resistance error from the rotor flux magnitude error. It is directly employed in the proposed observer structure, providing low sensitivity of the observer to the stator resistance variation. The influence of the stator resistance variation is compensated by introducing a non-linear magnitude and orientation feedback compensator in the observer.

$$
\hat{u}_{k}=u_{m}+j u_{p} .
$$

The switching function of the VSC flux magnitude controller $C_{m}$ is set to the error between the reference and estimated rotor flux magnitude:

$$
\frac{d \sigma_{m}}{d t}=-D_{m} \sigma_{m}=0, \quad \sigma_{m}=\Psi_{r}^{d}-\left|\hat{\Psi}_{r}\right| .
$$

The discrete part of the resulting unknown offset voltage $u_{m}$ is:

$C_{m}: u_{m}(k)=\frac{K_{m}\left(\left(1+T_{s} D_{m}\right) \sigma_{m}(k)-\sigma_{m}(k-1)\right)}{T_{s}}$.

The variation of the stator resistance $\Delta \hat{R}_{s}$ impacts the torque variation of the IM, expressed by the variation of the rotor flux error and torque:

$$
\begin{gathered}
\Delta T_{e}=\sigma_{m} T_{e}^{d} /\left|\Psi_{r}^{d}\right|, \\
\sigma_{p}=\Delta T_{e} \operatorname{sign}\left(\hat{\omega} T_{e}^{d}\right) .
\end{gathered}
$$

The switching function of the VSC orientation controller $C_{p}$ takes into account the torque variation:

$$
\frac{d \sigma_{p}}{d t}=-D_{p} \sigma_{p}=0
$$

When the torque is applied, the source of the connection between the torque error and the rotor flux error is the influence of the stator resistance error. The discrete form of the orientation correction signal becomes:

$$
\begin{aligned}
C_{p} & : u_{p}(k)=u_{p}(k-1)+ \\
& +\frac{K_{p}\left(\left(1+T_{s} D_{p}\right) \sigma_{p}(k)-\sigma_{p}(k-1)\right)}{T_{s}}
\end{aligned}
$$

Correction input signals influence the magnitude and orientation of the magnetic flux error, and thus make the proposed observer robust to the parameter variations. The resulting block diagram, which is suitable for providing the 


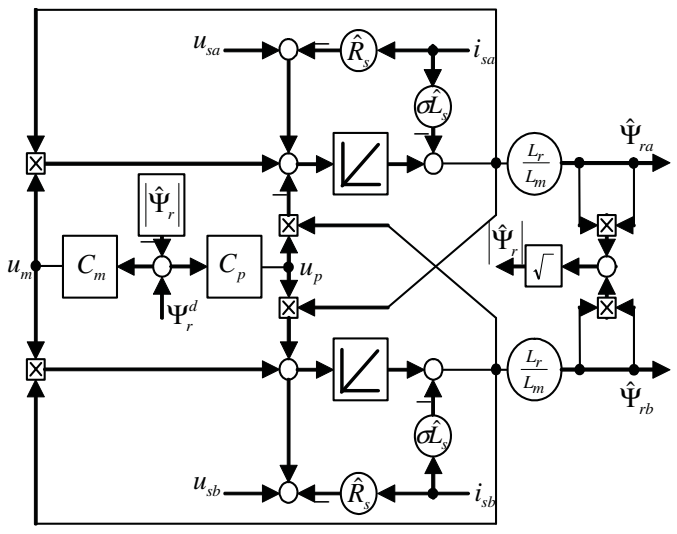

Fig. 4. Block diagram of the rotor flux observer

estimated stator and rotor fluxes of the IM, is shown in Fig. 4.

The estimated synchronous speed is now expressed with the following cross product:

$$
\hat{\omega}_{s}=\frac{1}{\left|\hat{\Psi}_{s}\right|^{2}} \frac{d \hat{\Psi}_{s}}{d t} \otimes \hat{\Psi}_{s}
$$

The estimated speed is computed entirely from the estimated rotor flux and its time derivative:

$$
\hat{\omega}_{r}=\frac{1}{p} \frac{\hat{\Psi}_{r} \otimes \frac{d}{d t} \hat{\Psi}_{r}}{\left|\hat{\Psi}_{r}\right|^{2}}
$$

The resulting estimated speed is subjected to high noise levels due to the derivative term that can be reduced by employing low pass filters.

The stability is computed only for magnitude rotor flux error, which is a common input for both, the magnitude and orientation errors of rotor flux observer. A Lyapunov stability criteria is used to verify the stability of the observer. The squared magnitude of the rotor flux error is set as a Lyapunov candidate function. In the selected case, a Lyapunov candidate function is, as required, always positive. The notation is adopted for complex numbers.

$$
V=\operatorname{Re}\left\{\left(\hat{\Psi}_{r}-\Psi_{r}\right)\left(\hat{\Psi}_{r}-\Psi_{r}\right)^{*}\right\} / 2 .
$$

The derivative of the Lyapunov function candidate must be negative:

$$
\dot{V}=\operatorname{Re}\left\{\left(\hat{\Psi}_{r}-\Psi_{r}\right) d\left(\hat{\Psi}_{r}-\Psi_{r}\right)^{*} / d t\right\}<0 .
$$

The derivative of rotor flux error is obtained using (2) and (3)

$$
\frac{d\left(\hat{\Psi}_{r}-\Psi_{r}\right)}{d t}=\Delta u_{s}-\Delta L_{s} \frac{d i_{s}}{d t}-\Delta R_{s} i_{s}+\hat{\Psi}_{r} u_{m}
$$

By using trigonometric functions for rotor flux description, when the amplitude of the rotor flux is known, the condition becomes:

$$
-\left|\hat{\Psi}_{r}\right|\left(\left|\hat{\Psi}_{r}\right|-\Psi_{r}^{d}\right)\left(\left|\hat{\Psi}_{r}\right|-\Psi_{r}^{d} \cos (\hat{\Theta}-\Theta)\right)<0 .
$$

If rotor flux angle error is sufficiently small than the condition is negative; therefore the observer is stable within given restrictions.

\section{IMPLEMENTATION}

The proposed approach is based on fast parallel processing and suitable for a Field Programmable Gate Array (FPGA) implementation. In such implementation it is possible to reproduce an ideal sliding mode process. However, with FPGA implementation, designer has the difficult task to characterize and describe the hardware architecture that corresponds to the chosen control algorithm. FPGA designers must follow an efficient design methodology in order to benefit from the advantages of the FPGAs and their powerful CAD (Computer Aided Design) tools. From a software point of view, Hardware description language (HDL) modeling system is based on using the variables that request logic values as well.

FPGA implementation of Table 1 is presented in Fig. 5, where signDI1, signDI2 and signDI3 present $S_{R}, S_{S}$ and $S_{T}$, respectively. Voltage sector states are presented by signU1, signU2, signU3. Inverter leg switching outputs are denoted as follows: TOP1 and BOT1 present states of top and bottom transistor in inverter leg R, TOP2 and BOT2 are presenting states of transistors in inverter leg $\mathrm{S}$, whereas TOP3 and BOT3 present states of transistors in inverter leg $\mathrm{T}$.

\section{RESULTS}

The sliding mode torque and flux algorithm is implemented onto the in-house developed DSP/FPGA board. The DSP/FPGA board contains Texas Instruments TMS 320C32 digital signal processor and Xilinx Spartan family field programmable gate array. DSP serves for A/D conversion and generating of the reference current. Replacing usual sequential calculation of algorithms on the DSP by parallel executable FPGA hardware increases the calculation speed. A/D conversion, which takes $5 \mu \mathrm{s}$ is the most critical operation regarding time. According to the fact, that A/D conversion takes most of the calculation time, switching frequencies up to $200 \mathrm{kHz}$ are theoretically possible.

Fig. 6 and Fig. 7 show transient response of estimated motor speed $\omega_{r}$ and torque $T_{e}$. Fig. 8 shows transient of motor phase currents $i_{s 1}, i_{s 2}$ and $i_{s 3}$. Desired speed 


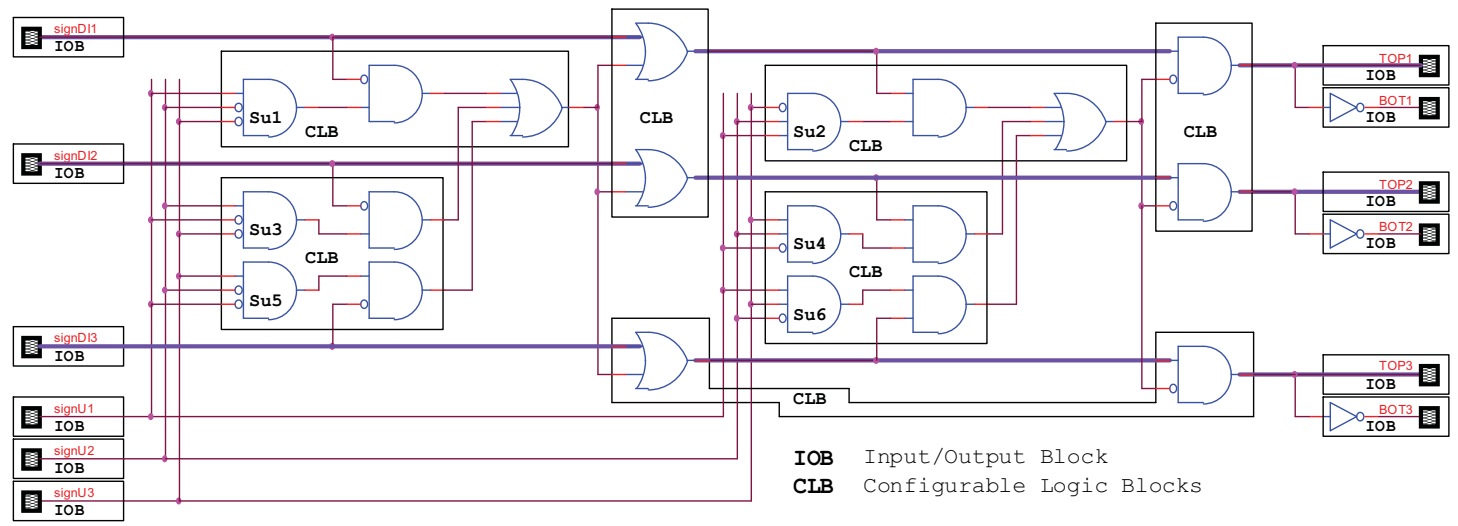

Fig. 5. FPGA schematic circuits

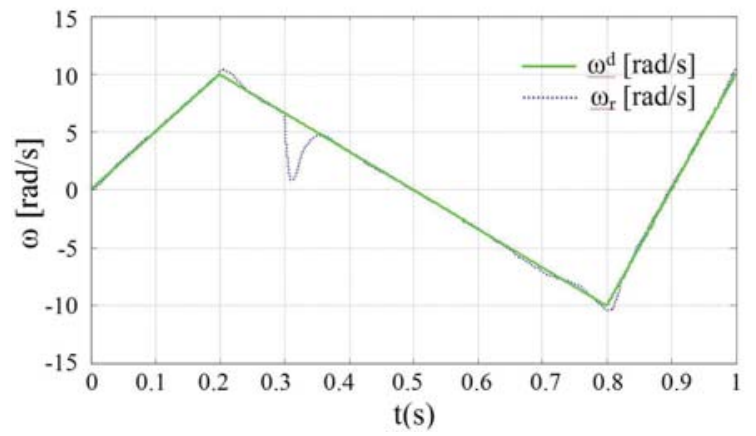

Fig. 6. Speed sensorless reference tracking

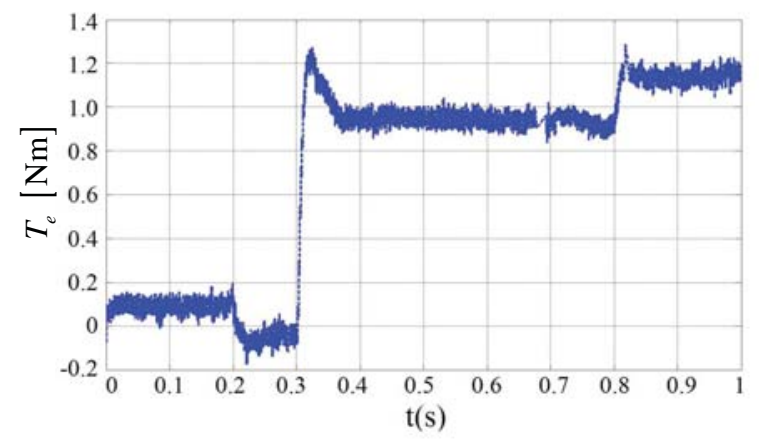

Fig. 7. Estimated torque transient

in experiment varies following the ramp signal and additional load is introduced at the time of $0.3 \mathrm{~s}$. Satisfactory tracking of speed, even in the case of slow transient through zero, is shown in Fig. 6. Estimated torque produced by the motor is shown in Fig. 7, presenting the impact of torque, required for acceleration, deceleration and load torque. Phase current, presented in Fig. 8 shows sinu-

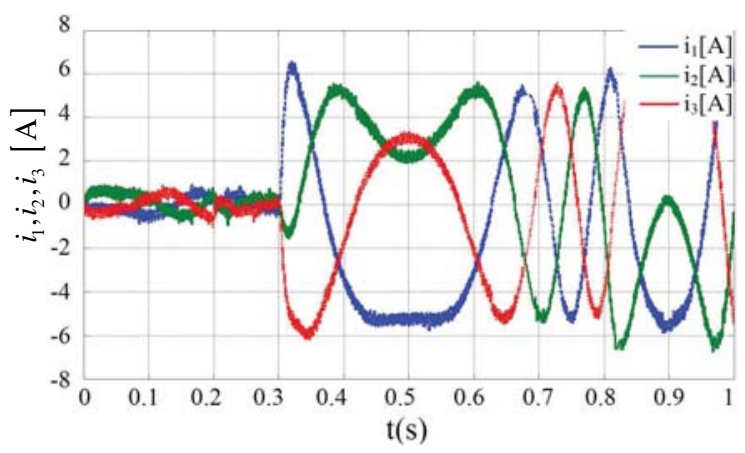

Fig. 8. IM phase currents

soidal signals, contaminated with satisfactory current ripple cost by switching. Likewise, torque ripple is within desired limits.

\section{CONCLUSION}

Overall functionality of the inverter and the performance of the proposed event-driven current control was checked by simulations first [10], and experimentally confirmed in this paper. Special attention is paid to the mapping of the proposed design approach into the schematic form for the FPGA implementation. Sliding mode rotor flux observer based on IM model is used to obtain rotor position and speed. This observer is sensitive to stator parameter changes and is improved with stator resistance adaptation. The proposed method shows good convergence and closed loop stability of the observer over a wide speed range, under model uncertainties, in particular those caused by stator resistance error.

Solutions based on specific hardware, that allow high concurrency, are suitable to be used in power electronics and motion control applications. 


\section{REFERENCES}

[1] J. Holtz, "Sensorless control of induction machines - with or without signal injection?," IEEE Transactions on Industrial Electronics, vol. 53, no. 1, pp. 7-30, 2006.

[2] J. Holtz, "Estimation of the fundamental current in low switching frequency high-dynamic medium voltage drives," in Proceedings of the 42nd IAS Annual Meeting, pp. 9931000, September 2007.

[3] A. Tilli and A. Tonielli, "Sequential design of hysteresis current controller for three-phase inverter," IEEE Transactions on Industrial Electronics, vol. 45, no. 5, pp. 771-781, 1998.

[4] V. I. Utkin, Sliding Modes in Control and Optimization. Berlin: Springer Verlag, 1992.

[5] D. Hercog, B. Gergič, S. Uran, and K. Jezernik, "A dspbased remote control laboratory," IEEE Transactions on Industrial Electronics, vol. 54, no. 6, pp. 3057-3068, 2007.

[6] G. Buja and M. Kazmierkowski, "Direct torque control of pwm inverter-fed ac motors - a survey," IEEE Transactions on Industrial Electronics, vol. 51, no. 4, pp. 744-757, 2004.

[7] C. Lascu, I. Boldea, and F. Blaabjerg, "Direct torque control of sensorless induction motor drives: A sliding-mode approach," IEEE Transactions on Industry Applications, vol. 40, no. 2, pp. 582-590, 2004.

[8] E. Mitronikas and A. Safacas, "An improved sensorless vector-control method for an induction motor drive," IEEE Transactions on Industrial Electronics, vol. 52, no. 6, pp. 1660-1668, 2005.

[9] A. Šabanović, K. Jezernik, and N. Šabanović, Variable Structure Systems: Towards the 21st Century, vol. 274/2002 of Lecture notes in control and information sciences, ch. Sliding modes applications in power electronics and electrical drives, pp. 223-251. Springer Berlin / Heidelberg, 2002.

[10] A. Polič and K. Jezernik, "Matrix based event-driven approach for current control design of vsi," in Proceedings of the 2005 IEEE International Symposium on Industrial Electronics, (Dubrovnik, Croatia), pp. 917-922, June 2005.

[11] A. Polič and K. Jezernik, "Closed-loop matrix based model of discrete event systems for machine logic control design," IEEE Transactions on Industrial Informatics, vol. 1, no. 1, pp. 39-46, 2005.

[12] C. Lascu, I. Boldea, and F. Blaabjerg, "Comparative study of adaptive and inherently sensorless observers for variablespeed induction-motor drives," IEEE Transactions on Industrial Electronics, vol. 53, no. 1, pp. 57-65, 2006.

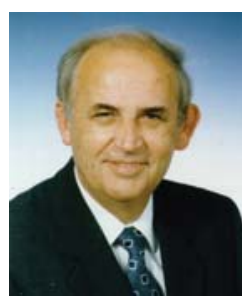

Karel Jezernik received B.Sc. (1968), M.Sc. (1974) and Dr. Eng. (1976) degrees in electrical engineering from the University of Ljubljana. In 1976 he joined the University of Maribor and in 1985 he became a Full Professor and Head of the Institute of Robotics. His research and teaching interests include automatic control, robotics, power electronics and electrical drives. Current projects in these areas are high precision tracking control in machine tools, DD robots and robust torque control in EV's. He consults on industrial servo control systems and other control applications.

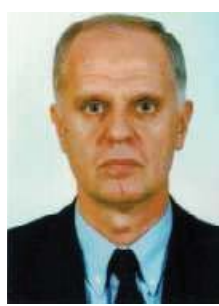

Asif Šabanović received B. Sc. (1970), M. Sc (1975), and Dr. Sc. (1979) degrees all in electrical engineering from University of Sarajevo From 1970 to 1991, he was with Energoinvest Institute for Control and Computer Sciences, Sarajevo. And then he was with the Department of Electrical Engineering, University of Sarajevo. Since 2000, he has been with the Faculty of Engineering and Natural Sciences, Sabanci University. He has been Visiting Researcher with the Institute of Control Science, Moscow, Russia (1975-1976) and Visiting Professor at the California Institute of Technology, Pasadena (1984-1985), Keio University, Yokohama, Japan (1991-1992), Yamaguchi University, Ube (1992-1993). He was head of CAD/CAM and the Robotics Department at TUBITAK-MRC, Istanbul, Turkey (1993-1995) and Head of the Engineering Department of B. H. Engineering and Consulting (1995-1999). His fields of interest include control systems, motion control systems, robotics, mechatronics, and power electronics.

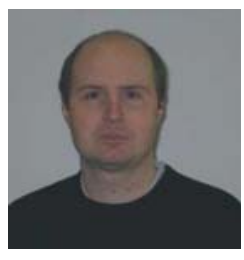

Miran Rodič received the B.Sc., M.Sc., and $\mathrm{Ph} . \mathrm{D}$. degrees from the University of Maribor, Maribor, Slovenia, in 1994, 1996, and 2000, respectively. He is currently a Teaching and Research Assistant in the Institute of Robotics, Faculty of Electrical Engineering and Computer Sciences, University of Maribor. His prime field of interest is the control of servodrives, especially control of ac drives.

\section{AUTHORS' ADDRESSES}

Prof. Karel Jezernik, Ph.D.

Asst. Prof. Miran Rodič, Ph.D.

Faculty of Electrical Engineering and Computer Science,

University of Maribor,

Smetanova 17, SI-2000 Maribor, Slovenia

emails: karel.jezernik@uni-mb.si, miran.rodic@uni-mb.si

Prof. Asif Šabanović, Ph.D.

Faculty of Engineering and Natural Sciences,

Sabanci University,

Orhanli-Tuzla, 34956 Istanbul, Turkey,

email: asif@sabanciuniv.edu 